\title{
NIHR $\mid$ Policy Research Unit

\section{Research engagement with policy makers: a practical guide to writing policy briefs}
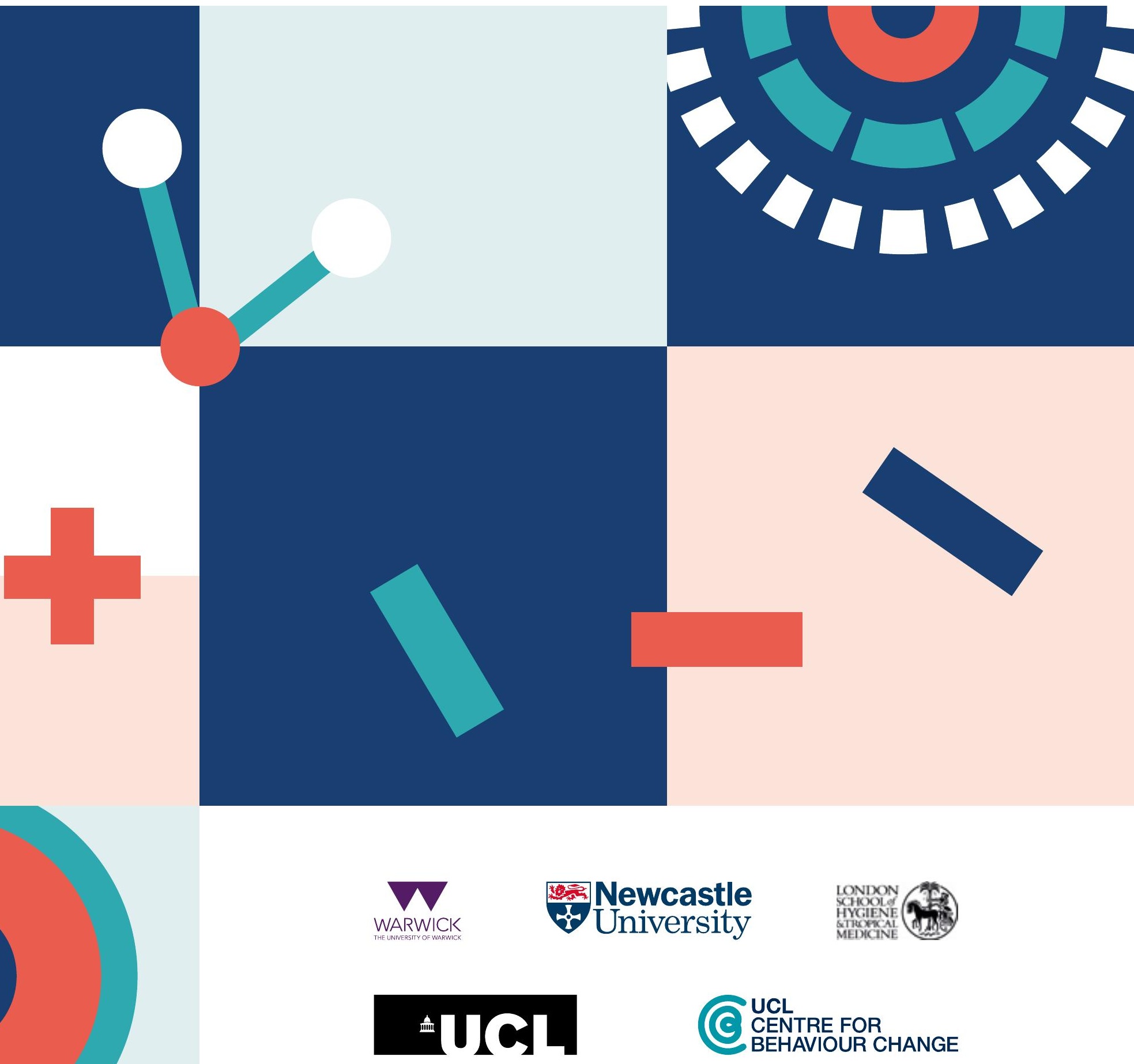


\section{Authors}

Antonopoulou, V. ${ }^{1}$, Chadwick, P. ${ }^{1}$, McGee, O. ${ }^{2}$,

Sniehotta, F.F. ${ }^{2,4}$, Lorencatto, F. ${ }^{1}$, Meyer, C. ${ }^{1}$,

O'Donnell, A. ${ }^{2}$, Lecouturier, J.2 ${ }^{2}$ Kelly, M. ${ }^{3}$, \& Michie, S. ${ }^{1}$
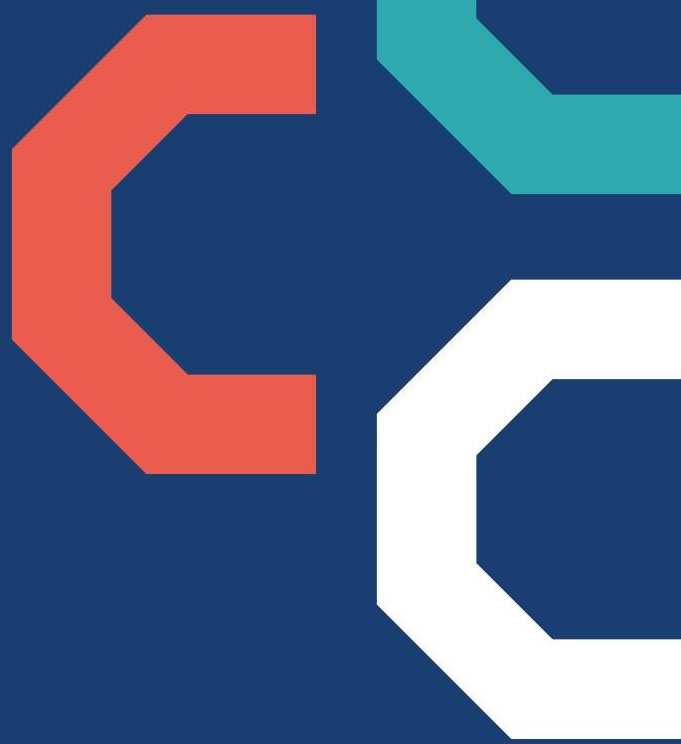

\section{Funding}

This project was funded by the National Institute for Health Research (NIHR) [Policy Research Unit in Behavioural Science (project reference PR-PRU1217-20501)]. The views expressed are those of the authors and not necessarily those of the NIHR or the Department of Health and Social Care.

1 NIHR Policy Research Unit in Behavioural Science - Health Psychology Research Group, Department of Clinical, Education and Health Psychology, University College London, 1-19 Torrington Place, WC1E 7HB, UK

2 NIHR Policy Research Unit in Behavioural Science - Population Health Sciences Institute, Faculty of Medical Sciences, Newcastle University, Newcastle upon Tyne, NE1 7RU, UK

3 NIHR Policy Research Unit in Behavioural Science - Primary Care Unit, East Forvie Building, Cambridge Biomedical Campus, Cambridge, CB2 OSR, UK

4 Faculty of Behavioural, Management and Social Sciences - University of Twente, Cubicus, De Zul 10, 7522NJ,

Enschede, The Netherlands 


\section{Contents}

About this brief \& Executive summary 4

1 Why write a policy brief? 6

2 Types of policy briefs

3 Tailoring a brief to the target audience 8

4 Who to involve when developing a policy brief 9

5 Developing actionable recommendations $\quad 10$

6 How to write a brief 11

7 Feedback and Reviewing 16

8 Dissemination 18

9 Impact monitoring and evaluation 19

10 Conclusion 20

11 Appendices 21

12 References 26 


\section{About this brief}

Effective communication between academics and policy makers plays an important role in informing political decision making and creating impact for researchers. Policy briefs are short evidence summaries written by researchers to inform the development or implementation of policy. This guide has been developed to support researchers to write effective policy briefs. It is jointly produced by the NIHR Policy Research Unit in Behavioural Science (BehSciPRU) and the UCL Centre for Behaviour Change (CBC). It has been written in consultation with policy advisers and synthesises current evidence and expert opinion on what makes an effective policy brief. It is for any researcher who wishes to increase the impact of their work by activity that may influence the process of policy formation, implementation or evaluation. Whilst the guide has been written primarily for a UK audience, it is hoped that it will be useful to researchers in other countries.

\section{Executive summary}

\section{This guide aims to help \\ researchers to:}

- Understand when and why you may consider producing a policy brief

- Know what features make a high-quality policy brief

- Have the tools to produce a high-quality policy brief based on research evidence

- Identify indicators to measure the impact of your brief 
A policy brief is a short publication specifically designed to provide policy makers with research evidence relating to a policy issue. Policy briefs provide a summary of findings for an issue or problem, targeted analysis, and, often, recommendations for policy. They are a strategy for promoting the use of evidence-informed policy and decision making. Writing a policy brief is a useful way to raise awareness of the current research conducted on a policy need and to succinctly communicate evidence-based recommendations. Briefs that have the following characteristics are more likely to realise impact:

- Professional, not academic - policy makers are primarily interested in what is known or not yet known about an issue and less interested in the finer details of research methodology

- Policy-focused - all aspects of the policy brief (from the message to the layout) need to be focused on the policy issue and provide a comprehensive but targeted argument within a limited space

- Understandable and succinct - briefs should be constructed using clear language, avoid the use of jargon, and provide a clear and easy to follow argument for a knowledgeable audience without specialist technical knowledge

- Evidence-based - all recommendations made by a brief need to be supported by evidence about the issue and the consequences of adopting particular policy options

- Feasible and actionable - the policy brief contains clear, actionable recommendations considered realistic by the target audience

\section{Key Recommendations}

- Provide a clear structure - policy briefs should be highly structured with content that meets needs of the audience, organised as: date, title, overview, recommendations/key research findings, introduction/ background, policy implications/recommendations, conclusions, acknowledgements, appendices.

- Tailor the policy brief to the intended audience - whenever possible, researchers should consult relevant policy makers about the issues they are working with, the questions it would be helpful to have answered, and their preferences for how to receive information. This will lead to more effective briefs.

- Make the brief as accessible as possible - researchers should involve a range of specialist and non-specialist reviewers in the development process. Patient and Public Involvement (PPI) can be particularly helpful in developing content that is non-technical and accessible to the widest possible audience.

- Summarise the evidence or key recommendation(s) researchers should summarise the evidence, indicate its level of conclusiveness, and be transparent about the methodology and criteria used for critical appraisal. If providing recommendations, researchers should ensure they are actionable and realistic to implement.

- Have a clear dissemination plan - writing a brief is only the first stage in creating policy-related impact for research. Researchers should develop a dissemination plan for the brief using multiple channels such as websites (e.g. the Open Science Framework (OSF)), webinars, social media and targeted communication.

- Monitor the impact of the policy brief - researchers should create a specific research plan, including methods and procedures, for how to measure the impact of their brief. 


\section{Why write a policy brief?}

Researchers may write policy briefs because they want research evidence to inform the way policy makers influence the lives of citizens. Evidence of the way research has influenced the development and/or implementation of policy is a powerful way that researchers can demonstrate the significance and impact of their work [1,2]. This is reflected in frameworks for assessing academic excellence that require evidence of 'real world' impact. Policy briefs can be initiated by researchers themselves, or be requested by stakeholders in government or organisations wishing to influence government.

Creating an effective policy brief starts with having a clear understanding of the ways in which research evidence could shape policy $\left.{ }^{3,4}\right]$. The following questions can be used by researchers to develop their understanding of the potential policy impact of research evidence $\left[{ }^{13,35}\right]$ :

1. Why does this research matter for public policy?

2. Is there a current policy debate/initiative for which the policy brief is relevant?

3. Who is the target audience?

4. Are there particular areas or public policy issues for which research findings are significant?

5. What policy options are you offering to policy challenges?

6. What are the implications of the research findings?

7. What will be the indicators of impact?
Research is most helpful to policy makers when it answers a specific question. Policy makers and researchers can be interested in the same issue but have different frames of reference, and different ways of asking questions [ $\left.{ }^{4,8,9}\right]$. Policy makers are a diverse group of professionals with varying backgrounds. Some policy makers may need support to frame policy questions in ways that research can answer. Others may need support with developing their ideas about how research may inform an evolving policy issue. In all cases, researchers should try to establish mutually respectful working relationships with policy makers to shape the development of a policy brief in ways that will have maximum impact (see also section 4 on

"Who to involve").

Policy making is a cyclical process and it is possible to influence policy at all stages in its formation, implementation or evaluation. The type and content of a policy brief should be informed by the needs of the stakeholders and the specific stage of the policy cycle $\left.{ }^{5,6}\right]$. 


\section{Types of policy briefs}

\section{Policy briefs vary in their purpose. These include} synthesising academic research in one place, providing policy makers with policy options and to inform briefings for Government ministers and officials. There are two main types of policy brief:

- An evidence-focused brief providing balanced information to support policy makers' decision making

- An advocacy brief arguing in favour of a particular course of action

Evidence-focused briefs are usually created in response to requests from analysts, policy makers or ministers who wish to better understand the evidence behind a policy option under consideration [14,11]. Advocacy briefs are usually created when the researcher(s) believe that evidence strongly supports a particular course of action for policy and wishes to summarise this to influence Government decision making.

Research and expert opinions suggests that effective policy briefs are characterised by independence and transparency in their analysis [12,7]. This means that they are free from vested interests (e.g. political or corporate influence) and make clear the position from which the authors are writing.
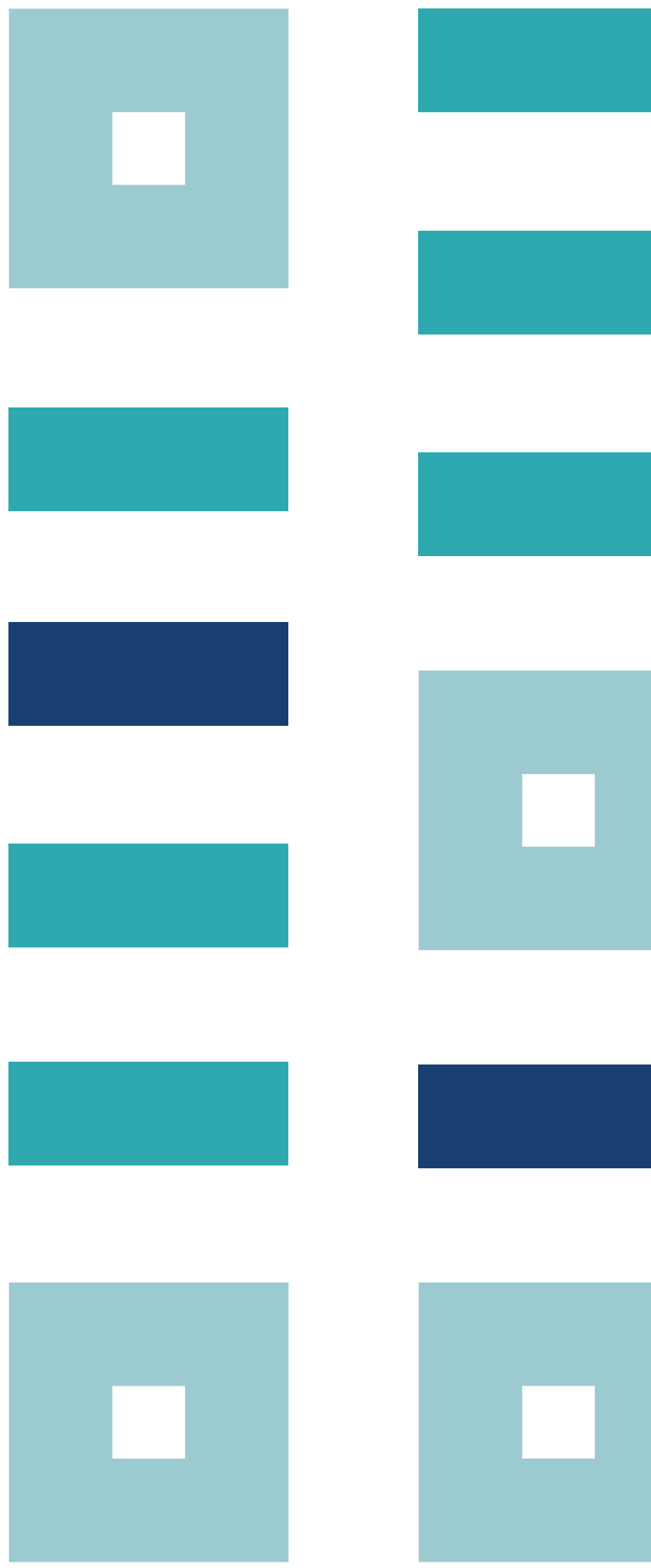


\section{Tailoring a brief to the target audience}

Policy briefs are targeted communications and can be written for a variety of policy actors and decision makers [5,4]. It is therefore critical to identify and understand the intended audience for a brief. This means identifying their needs and preferences for communications, as well as their roles and responsibilities to ensure they are in a position to implement or enable implementation of the recommendations $\left[{ }^{33}\right]$. Potential audiences may include individuals within government such as ministers, parliamentarians (MPs and the members of the House of Lords), civil servants (e.g. policy analysts, programme managers and leads, government researchers), political advisers (e.g. Special Advisors), as well as employees of organisations in the wider political infrastructure such as those in think tanks, lobbying firms and campaigners from charities and nongovernmental organisations (NGOs). Each of these audiences may have different needs and preferences for receiving information about research. Understanding the target audience at the outset will help with developing an effective brief [ $\left.{ }^{32,34}\right]$. Tailoring can be effectively achieved using the following:
- Make it relevant. Policy makers are constantly inundated with information. Do not write about a subject just because it is new and exciting to academics; it must have some relevance to current issues. In the case of Government this is usually issues on the political agenda, for example, imminent decisions on funding or legislation.

- Make it timely. Make sure the policy brief reaches the target audience before a key course of action or policy decision about the issue is made. Be mindful of the electoral timetable and the pressures that politicians, councillors, and policy officers experience to deliver relatively speedy impact. Provide timescales when talking about future developments but ensure that ambitions for timetables do not exceed what is reliably deliverable (see also section 5 on "Developing actionable recommendations").

- Localise. Members of Parliament (MPs) and local councillors represent the communities within their electoral constituencies. Think about whether the content of the brief can be connected to local or regional issues that they are likely to be interested in. Ways of identifying the issues the audience may be interested in include:

- checking their twitter accounts to see the topics they most often post about

- reviewing relevant documents e.g. in the UK, Hansard, a searchable, verbatim report of what is said in Parliament, or the reports of local government committees [ ${ }^{36}$ ]

o reviewing individual webpages

o identifying membership of any committees or groups, such as Parliamentary Select Committees or other special interest groups, and local government associations [ ${ }^{32,33}$ ]

o consult local petitions 


\section{Developing actionable recommendations}

\section{Policy makers are extremely time-pressured and, most, although not all, policy makers are primarily interested in the actions recommended by a policy brief - i.e. what does research suggest should be done?}

Recommendations in policy briefs should be actionable. This means being clear about who the recommendation refers to (e.g. specific health care professional groups, researchers, funders), the actions they should take (e.g. adopt a particular course of action, conduct studies on an issue, fund a particular service or research study), and the timeframe and sequence for taking such actions if appropriate. Actionable recommendations make it very clear about what the evidence suggests should happen, as well as enabling researchers to evaluate the impact of the brief (see section 9 on "Impact monitoring and Evaluation").

\section{Table 1: The APEASE criteria}

(adapted from West at al., 2019 [24])
If the brief involves making recommendations about the content or implementation of a policy it can be helpful to have considered the criteria which may influence whether a recommendation would successfully deliver the intended policy outcome. There are several frameworks that researchers and policy makers can use to draft actionable and effective recommendations $\left[{ }^{23,22,30}\right]$. The APEASE criteria can be used to draft recommendations, or alert policy makers to factors that may influence whether recommendations will deliver the intended outcome [24]. The APEASE criteria are listed and described in Table 1.

Recommendations should reflect the state of relevant evidence; it is important not to be drawn into making recommendations when the evidence does not support a specific course of action, or support one course of action over another $\left.{ }^{16}\right]$. Make clear the limitations of the available evidence so that policy makers and evaluators can differentiate between evidence-based recommendations (i.e. the content of the brief), and politically-based decisions (i.e. courses of action which may not reflect the advice offered in the brief).

\section{Criterion}

Acceptability

Practicability

Effectiveness and cost-effectiveness

Affordability

Side-effects/ safety

Equity

\section{Description}

To what extent will the recommendation be acceptable to key stakeholders? This includes policy makers, ministers, group, potential funders, practitioners and relevant community and commercial groups affected by the recommendations

Can the recommendations be implemented at scale within the intended context, and the available material and human resources? What would need to happen to ensure that the resources and personnel were in place to implement the recommendations within relevant timeframes, and to deliver sustainable change?

How effective will the recommendations be in achieving the policy objective(s)? How far will they reach the intended target group and how large an effect will they have on those who are reached?

Are the recommendations affordable within the context and resources available? Can the necessary budget be found for them? Will they provide a good return on investment?

Are there any potential unintended adverse or beneficial outcomes of implementing the recommendations?

To what extent will the recommendations increase or decrease differences between advantaged and disadvantaged sectors of society? 


\section{How to write a brief}

\author{
Policy briefs should be presented in formats and \\ language that policy makers are familiar with [12,1]. \\ There are no universally accepted rules as to what \\ policy briefs should contain; the following guide \\ can be adapted to suit the intended purpose of \\ the brief.
}

\subsection{Length \& Style}

There is no prescribed length for a policy brief, however most policy briefs are 1-4 pages long, and rarely exceed 8 pages $\left.{ }^{[12,13}\right]$. Researchers could discuss preferences for length and style directly with policy makers before starting to write the brief.

Length will depend on the purpose of the brief, the complexity of the issue, and the target audience. A "onepager" may present talking points with a single figure to illustrate key data. A more complete exploration of an issue describing a variety of policy options could extend up to 8 pages $\left.{ }^{[12}\right]$. Use of images and infographics, or inclusion of a case study may extend the length but increase the readability. Paragraphs should be short and communicate a single idea. Use the first sentence in a paragraph to communicate the most important point you wish to make and use the rest to add supporting detail, boldface can be used to draw attention to key points. Define any unfamiliar terms and spell out the first use of any terms that are commonly abbreviated in full, thereafter use abbreviations.

\subsection{Structure \& Content}

Policy briefs typically start with a executive summary of key points and clearly signpost the reader to other sections, providing efficient access to the most relevant information [5,8]. Table 2 displays the different sections that might be included in an effective brief along with recommendations for the location of each section within the document.
Recommendations for the content of different sections are provided below $[5,8,12,13,25]$.

- Date and disclaimer. The date when the brief is published enables people to assess the relevance of the work when reading it. Briefs should also contain a disclaimer stating the brief is based on the evidence available at the date of publication.

- Title. The title should communicate the key message of the research findings in a way that captures policymakers' attention: short, to the point and catchy.

- Executive Summary. Start with a summary that outlines the key points of the briefing: the policy issue, how the research findings address it and your conclusions. This may be the only thing the policymaker reads, or it may influence whether they go on to read the rest of the brief. This 'executive summary' is the equivalent of an abstract for a journal paper.

\section{- Recommendations/Key Findings.}

Recommendations, options or key findings should be presented at the beginning of the brief as this may be the only thing that policy makers read. Depending on the degree of conclusiveness of the relevant evidence, it is acceptable not to offer policy recommendations or options. If making recommendations make sure that they are specific and actionable and clearly linked to evidence (for further details see section 5 on Developing actionable recommendations). If presenting key findings make sure they are clearly linked to the policy question.

- Introduction/Background. The introduction should describe the broad goals and underlying motivations for the brief. It can describe current policy approaches and the evidence upon which they are based. The background can present the broader context and historical rationale for the issue if this is helpful for understanding the brief. This section 
should describe the status of existing academic/ scientific work on the issue, highlight knowledge gaps that need answers, and present the research and policy question.

- Research Findings. Present the findings and explain how these relate to the current scientific knowledge on the topic. Merely presenting data is not sufficient. Describe potential counterarguments and alternative interpretations of the findings, particularly ones that policy makers are likely to face when trying to use the evidence. Declare potential bias based on the data sources. Unless you are sure that your audience wants and needs a lot of technical detail, include minimal detail and present this as an Appendix or hosted on a website. Provide links for interested readers to access more detailed information such as a full research paper or project website. Relevant data should be presented in the format that best communicates the information you wish to present (see also paragraph on visuals further down this section).

- Policy Implications. This section should describe the implications of the findings for policy or future research. This may include recommendations for particular actions or policy options for a range of fields at the micro, sectoral and institutional levels. Offer clear justification for proposing or highlighting actions or options. Present the advantages and disadvantages of any policy option or action and signpost any trade-offs involved. It is advisable to keep the findings, policy implications and recommendations separate to help policy makers distinguish between what the scientific evidence says and what the implications for policy are.

- Conclusion(s). This section describes how the evidence and recommendations fit into the big picture and reasons for creating the brief. It should highlight the key findings or recommendations and outline what will happen if the decision-maker does or does not act on the recommendations.
- Boxes \& Visuals Graphics. Photographs and infographics are powerful ways to communicate a message. Use graphics such as figures, tables, charts or diagrams and images where suitable to help your brief be more eye-catching, appealing and understandable. All graphics should be easy to understand and not replicate information within the text but not used as a substitute for text when discussion of the findings is needed. All graphics should be appropriate for their intended purpose and appropriately labelled. For example, line graphs to illustrate trends, pie charts to illustrate proportions, and bar charts to show differences between groups. Infographics that are primarily for communication to the public could be annexed.

- Funders, Acknowledgments, Author Contact Details \& Statement of Interest. State any funding used for the research, and also the author's current positions and contact details for further communication. If the policy brief is being produced by an institution a statement of interest may be needed.

- Appendices. Although the brief is a short and targeted document, authors can provide additional information to support the recommendations in an appendix, but only if necessary.

- Logos. It is important to ensure that briefs are appropriately branded to ensure that the researcher, group or institution that produced it recieves credit. Logos are an effective way to communicate who created the brief. Policy makers prefer to read recommendations originating from trusted and well-known institutions [ [ $]$. When policy briefs are produced by more than one group, insititution or programme think about what source the target audience might trust the most. Information about researchers, groups, programmes and institutions could be included in the acknowledgements or in a side-box [5]. 
Table 2: Typical sections of a policy brief (adapted from Wong et al. 2017 [ $\left.{ }^{12}\right]$ )

\begin{tabular}{|c|c|c|}
\hline Section & Required? & Position in document \\
\hline Title & Necessary & Beginning \\
\hline Overview (or Executive Summary) & Optional & Beginning \\
\hline Recommendations/focus on key research findings & Necessary & Beginning \\
\hline Introduction & Necessary & Middle part \\
\hline Main text/Discussion (potentially broken down into sub headings) & Necessary & Middle part \\
\hline $\begin{array}{l}\text { Policy implications (can be placed at the end, if not presented } \\
\text { earlier in the brief) }\end{array}$ & Necessary & Beginning or end \\
\hline Conclusion & Optional & End \\
\hline References & Necessary & End \\
\hline Contact details/Author info & Necessary & End \\
\hline Appendix & Optional & End \\
\hline Boxes and sidebars & Optional & Middle or end \\
\hline Cases & Optional & Middle or end \\
\hline Tables & Optional & Middle or end \\
\hline Graphics & Optional & Middle or end \\
\hline Photographs & Optional & Middle or end \\
\hline
\end{tabular}

\subsection{Characteristics of effective briefs}

Various forms of evidence can be included in policy briefs, drawing upon a wide variety of epistemologies and methodological frameworks [7,5]. Using a formal and rigorous methodology can ensure accuracy and credibility of the evidence presented [ $\left.{ }^{28}\right]$. Research summaries should briefly describe the methods used to gather evidence and, if from multiple evidence sources or methodologies, describe how these have been combined [11]. All briefs should clearly indicate any uncertainties, risk of bias and inconclusive evidence in relation to the social contexts relevant to the brief $\left[{ }^{9,7}\right]$.

\subsection{Accuracy and credibility of sources}

Accuracy refers to content that is well-defined, and drawn from reliable sources using transparent and rigorous methodologies $\left.{ }^{[1,8}\right]$.

Ways to increase the accuracy of the brief include:

- There is no one single way of collecting evidence to inform policymaking. Different methodological approaches are appropriate for different policy issues. Acknowledge the strengths and limitations of the methods used in the research you are summarising and the methods you used to synthesise the research that informed the brief [15]. This allows readers to understand the nature and limits of the presented evidence $[2,11]$. A policy maker reading the brief will have more confidence if you are transparent in the limitations and volunteer where evidence is contrary to expectation. 
- Use high quality evidence-based information from trusted sources. Follow a robust process for selecting these sources. This means that policy makers can trust the evidence provided and use it to make evidence-informed decisions [ ${ }^{28}$. Discrepancies between evidence collected from different sources often arise from variations in definition and methodology. Explain how quotes, figures and statistics have been calculated [5]. If there is an important caveat attached to a particular statement, make sure that it is mentioned at the start of the brief and reiterated whenever it is relevant.

- When reporting quantitative findings, avoid using general terms like 'large' or 'most of' without qualification. Be as specific as you can [ $\left.{ }^{5}\right]$. Avoid using superlatives and emotive language that can be quoted out of context.

- In cases where using a concrete event can help illustrate a point clearly - for example, about public reaction to a decision in the field you are addressing - but cannot refer to specific places or people for reasons of privacy or political sensitivity, it is best to use an anonymised but representative case study or scenario [15].

- Attribute any statements that you have obtained from a specific source and indicate if you are giving a direct quotation. Be clear and transparent about the reviewing processes of the brief, particularly if presenting a new study or new findings. State whether external peer review has taken place or not.

\subsection{Conclusiveness of the evidence}

In cases of high scientific uncertainty, disagreement or inconclusiveness of the evidence, it is important to indicate the degree of uncertainty and discuss it. In an evolving research landscape, an effective brief should state the level of conclusiveness of the evidence base, either narratively, or where appropriate along the lines of the UK's National Institute for Health and Care Excellence (NICE) critical appraisal and evaluation methods [28, 29].

Ways to address uncertainty in the brief include:

- Try to reflect the diversity of opinions on an issue, and to make its nature explicit, in terms of whether there is general consensus or widespread controversy on the issue or some of its elements.

- You may need to examine the limitations of science in addressing the issue, for example, due to lack of precise reporting of intervention content or due to publication bias of under-reporting the negative or inconclusive results [9,11,31].

- Do not be afraid to omit direct conclusions if you feel that none can be drawn based on the available evidence. Any policy decision is a political decision, not a scientific one and, therefore, politicians need to manage uncertainty and make such decisions [ $\left.{ }^{16}\right]$. 


\subsection{Summary advice}

Table 3 summarises the key aspects of style and content that can help achieve the criteria for an effective policy brief.

Table 3: Summary guidance for writing policy briefs

\begin{tabular}{|c|c|c|c|c|c|}
\hline \multirow{2}{*}{$\begin{array}{l}\text { Features } \\
\text { of the } \\
\text { brief }\end{array}$} & \multicolumn{5}{|c|}{ Principles of effective policy briefs } \\
\hline & $\begin{array}{l}\text { Professional, } \\
\text { not academic }\end{array}$ & Policy-focused & $\begin{array}{l}\text { Understandable } \\
\text { and accessible }\end{array}$ & Evidence-based & $\begin{array}{l}\text { Feasible and } \\
\text { actionable }\end{array}$ \\
\hline Style & $\begin{array}{l}\text { Pitch your brief at } \\
\text { an intelligent, } \\
\text { non-expert } \\
\text { audience. }\end{array}$ & $\begin{array}{l}\text { Ensure that all } \\
\text { information is } \\
\text { clearly related } \\
\text { to the policy } \\
\text { question. }\end{array}$ & $\begin{array}{l}\text { Assume the } \\
\text { reader has } \\
\text { no specialist } \\
\text { knowledge of } \\
\text { the area. } \\
\text { Ensure each } \\
\text { paragraph has } \\
\text { only one key point. } \\
\text { Define any } \\
\text { technical terms } \\
\text { used. } \\
\text { Use open access } \\
\text { sources as much } \\
\text { as possible and } \\
\text { use hyperlinks } \\
\text { to key sources of } \\
\text { evidence. }\end{array}$ & $\begin{array}{l}\text { Bring together } \\
\text { existing and new } \\
\text { evidence with a } \\
\text { clear and logical } \\
\text { structure and } \\
\text { cohesion. } \\
\text { Describe any } \\
\text { identified gaps in } \\
\text { the evidence base } \\
\text { and the research } \\
\text { required to fill } \\
\text { them, highlighting } \\
\text { why it is needed to } \\
\text { answer the policy } \\
\text { question. }\end{array}$ & $\begin{array}{l}\text { Use examples and } \\
\text { visual displays (e.g. } \\
\text { tables, graphs, } \\
\text { diagrams) to } \\
\text { illustrate your } \\
\text { points and make } \\
\text { them visually } \\
\text { accessible. }\end{array}$ \\
\hline Content & $\begin{array}{l}\text { The brief should } \\
\text { be knowledge } \\
\text { rather than } \\
\text { methodology } \\
\text { focused. }\end{array}$ & $\begin{array}{l}\text { Ensure there is } \\
\text { a clear policy } \\
\text { question. } \\
\text { Tailor the way } \\
\text { evidence is } \\
\text { identified and } \\
\text { synthesised to } \\
\text { reflect the nature } \\
\text { of the policy } \\
\text { question. } \\
\text { Consider } \\
\text { including policy } \\
\text { recommendations } \\
\text { for a range of } \\
\text { fields at the } \\
\text { micro, sectoral } \\
\text { and institutional } \\
\text { levels. }\end{array}$ & $\begin{array}{l}\text { Clearly describe } \\
\text { the key research } \\
\text { findings and their } \\
\text { implications. } \\
\text { Make sure } \\
\text { that the } \\
\text { evidence clearly } \\
\text { supports any } \\
\text { recommendations } \\
\text { made. }\end{array}$ & $\begin{array}{l}\text { Use systematic } \\
\text { methods and } \\
\text { make these } \\
\text { transparent so } \\
\text { that readers can } \\
\text { assess how you } \\
\text { reached your } \\
\text { conclusions. } \\
\text { Present the } \\
\text { evidence for your } \\
\text { argument in a } \\
\text { clear and logical } \\
\text { manner. } \\
\text { Be explicit } \\
\text { about any } \\
\text { methodological } \\
\text { limitations and } \\
\text { the strength } \\
\text { of evidence } \\
\text { presented. }\end{array}$ & $\begin{array}{l}\text { Ensure all } \\
\text { recommendations } \\
\text { are actionable. }\end{array}$ \\
\hline
\end{tabular}




\section{Feedback and Reviewing}

Getting feedback is the best way to check readability and accuracy and enhance writing quality. If time permits, send a draft of the brief to all the main stakeholders consulted before presenting it. This is a good way of checking accuracy and balance. If you do this, it is important to have a clear deadline to manage expectations and fulfil your own deadlines.

It is important to ensure anyone you have consulted is happy with any information you have attributed to them before you publish. Otherwise, they may publicly disagree with the brief $\left[{ }^{26}\right]$. However, it is also important to make clear the nature of the consultation, e.g. receiving feedback on issues of accuracy without undermining the independence of the brief.
It can also be helpful to have someone with no expertise in the subject read your brief. It is easy to lose readability and meaning with such a condensed piece, and having a fresh pair of eyes will help identify points that require more clarity [ $\left.{ }^{26}\right]$. For example, having people from PPI groups review the work is likely to broaden the audience who can be engaged by the brief and will also add a different perspective $\left[{ }^{27}\right]$.

Table 4 presents a checklist which can be used to review a policy brief ${ }^{1}$.

Table 4: Policy Brief checklist for reviewing and editing

\section{Argument flows clearly}

\begin{tabular}{|c|c|c|c|}
\hline Yes & Needs work & & Comments and suggestions \\
\hline & & Aim is clear & \\
\hline & & Brief summary of research findings with a policy focus & \\
\hline & & Conclusion is clear at the outset & \\
\hline & & Problem is clear and specific & \\
\hline & & $\begin{array}{l}\text { Recommendations flow logically from the evidence } \\
\text { presented }\end{array}$ & \\
\hline & & $\begin{array}{l}\text { Recommendations are logically prioritised and } \\
\text { actionable }\end{array}$ & \\
\hline & & $\begin{array}{l}\text { All information is necessary for the development } \\
\text { of the argument and covers all aspects }\end{array}$ & \\
\hline & & Paragraphs are short and restricted to a single idea & \\
\hline
\end{tabular}

1 This checklist has been adapted from the checklist produced by the Johns Hopkins Bloomberg School of Public Health, Baltimore, $\mathrm{MD}$ (JHSPH) checklist which is available at: https://www.spssi.org/index.cfm?fuseaction=document.viewdocument\&ID= 3F28EB86AE4CA3BB2EE025BE0093BF0461E1D7156B364C89ED0026166A91E7BFA6952AE18DBE281F122D1C5A3A1CBAA2 
Table 4: (continued)

\section{Content is appropriate for the audience}

\begin{tabular}{l|l|}
\hline Yes & Needs work
\end{tabular}

Importance to the audience is clear

Recommendations are appropriate for the audience

Understandable without specialised knowledge

\section{Language is clear, concise and engaging}

\begin{tabular}{|c|c|c|c|}
\hline Yes & Needs work & & Comments and suggestions \\
\hline & & Title is short and snappy & \\
\hline & & Words are not unnecessarily complex & \\
\hline & & Jargon is not used & \\
\hline & & $\begin{array}{l}\text { Sentences are not cluttered with unnecessary } \\
\text { words or phrases }\end{array}$ & \\
\hline & & Text is engaging (e.g. active voice) & \\
\hline
\end{tabular}

\section{Data are presented effectively}

\begin{tabular}{l|l}
\hline Yes & Needs work
\end{tabular}

All data are necessary for the argument

Data are easy to understand

Data are presented in the most appropriate format

Graphics are not redundant with text

Graphics are appropriate for the data presented and appropriately labelled

\section{Visual cures to help the reader navigate and digest information}

\begin{tabular}{|l|l|l|}
\hline Yes & Needs work & \\
\hline & White spaces and margins sufficient \\
\hline Text is broken into sections with identifiable focus \\
& $\begin{array}{l}\text { Headings cue the key points to follow } \\
\text { Key points are easy to find }\end{array}$ \\
\hline
\end{tabular}




\section{Dissemination}

\section{Dissemination and knowledge translation is most effective if considered as an integral part of the policy brief development process. Therefore, a strategic dissemination plan created in the early stages of developing the brief clearly detailing all steps and planned activities (such as workshops or webinars etc.) can be very useful. Researchers can identify ways in which they can publicise their messages to the relevant knowledge users and gauge interest for further work.}

Policy briefs can be disseminated in numerous ways: via social media, websites, newsletters, meetings and mailings to a targeted audience (e.g. MPs' surgeries held locally). It is best to make your brief available both electronically and in hard copy where required, putting the electronic version online so that as many people as possible can have access to it. However, this should be cleared by those commissioning policy briefs in case there is a security or confidentiality constraint and it is always important to check the funder's publishing timescales.
When compiling a distribution list for the policy brief, consider targeting those with a specific interest in your subject, rather than sending out hundreds of copies in the hope that someone will read it. You can often find out who the most appropriate people to send the brief are by looking at who has been associated with the topic you're covering, searching for media articles and interviews, parliamentary discussions, or actively campaigning on the topic of your interest. Reaching a smaller number of people who are more likely to read the brief is more valuable than a larger number of people who may never read it $\left.{ }^{26,8}\right]$. Moreover, policy makers often take an interest in what other stakeholders have seen or commented on a piece - for example, the UK Department of Work and Pensions would be interested if a disability equality charity organisation such as SCOPE had any views on a research piece about independent living, as SCOPE are then likely to go on to lobby politicians of various stripes.

Do follow up the policy brief after a certain time period or set a reminder to follow up. Personal contact with a policymaker can make a real difference, especially as policy makers tend to rely on informal but trusted contacts for advice [ $\left.{ }^{34}\right]$. Practical tips on engaging with policy makers for following up the brief include emailing or making a call to the policymaker to enquire if they need any clarifications or additional resources or information after reading the brief. It is also a good idea to invite the policymaker(s) to a seminar or an event to discuss the brief in more depth [3]. 


\section{Impact monitoring and evaluation}

\section{One reason why researchers should consider writing policy briefs is to increase the impact of their work. However, demonstrating and assessing policy impact is not easy, as there is not always a direct pathway from evidence to policy impact and that impact can take many forms, not always directly identifiable [20,19,21]. This section outlines the different ways that researchers can think about measuring policy impact.}

Measuring the impact of policy briefs on policymaking is widely acknowledged to be a complex process $\left[{ }^{10,18}\right]$. Impact is achieved through several steps that include helping relevant audiences to discover, understand and apply relevant research. Within UK academia the Research Evaluation Framework evaluates the impact of research beyond academia as well as academic excellence, defining impact as "an effect on, change or benefit to the economy, society, culture, public policy or services, health, the environment or quality of life, beyond academia." (REF Guidance, 2021).

Research can influence policy in a number of different ways which can make it difficult to identify whether and how research has influenced policy [19]. Difficulties in attributing a policy impact to a specific piece of research include:

- the original piece of research may be re-interpreted in the policy process or it may be adapted to particular contexts and transformed during the process

- multiple influences at different stages of research and policy translation may also function to diffuse knowledge

- policy change is dynamic and is the product of various decisions that result from political compromises

- the most difficult impact to track is that of recommending not to take a certain path of action.
A policy relevant definition of research impact should take account of the fact that different impact may be suitable for different research projects, different audiences, disciplines and may reflect different objectives. Thus, the evaluation plan is likely to integrate a mix of quantitative indicators and qualitative reviews [22]. It is also important to:

(i) specify timescales involved (short term versus longer term)

(ii) measure changes in the medium- to longer- term; assess progress against specified outcomes, such as policy and funding changes, policy maker attitudes, and help verify that the change has taken place

(iii) track changes even if small

The UCL Policy Impact Unit has produced a list of example process and outcome indicators to assess progress against specified outcomes, such as policy and funding changes, policymaker attitudes, and help verify that the change has taken place. Whilst not exhaustive, it can serve as a guide for the evaluation process. These example indicators can be found in Appendix 2. 


\section{Conclusion}

The way research evidence is communicated to policy makers is critical to how it is received and acted upon. Writing a policy brief requires a systematic approach to preparation, design and implementation. This guide aims to enable authors to provide clear and succinct arguments, based on current research evidence in context and propose recommendations realistic to the target audience. This should include synthesising evidence rigorously and concisely and presenting evidence-based findings and policy recommendations in a clear, accessible format.

\section{Acknowledgements}

We would like to thank the UCL Public Policy Unit and the UCL Policy Impact Unit for providing useful resources and for reviewing the guide.

We would also like to thank PRU colleagues Graham, F., Grimani, A., Goffe, L. and Tang, MY., and the PRU PPI members for reviewing and commenting on the guide: Edwards, S., Soulsby, I., Green, D., Kemp, C., Bryant, V., McKenzie, M. \& Shah, S. and to Anita Tibbs for administrative support.

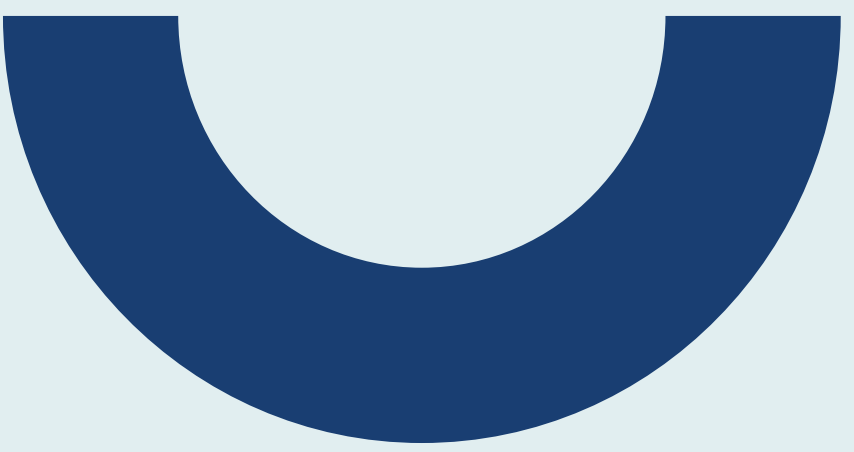




\section{Appendices}

\section{Appendix 1 - Example template for writing a policy brief (POST)}

Date: [DD/MM/YY]

[Title (aim for no more than ten words)]

[Sentence explaining the policy issue that needs resolving and why.

Sentence explaining what evidence suggests the solution to this issue is.]

\section{Context}

[Sentence (aim for no more than fifteen words) summarising the policy problem. Sentence on the scope of the problem (who/what does it affect, where and how often?). A few sentences on the background of the issue with evidence showing that this is a policy problem (use engaging statistics from reputable sources).]

\section{Research Evidence}

[Summary sentence on the research evidence you wish to present. Sentence on the methodology used. Sentence on the limitations (is the evidence generalizable? Is it exploratory work?). A few sentences on the wider research context (How much evidence is there? Is there consensus? Is there uncertainty?).]

\section{Key Findings}

- [Sentence presenting a key finding in the research evidence.]

- [As above.]

- [As above.]

(Aim for no more than 3 key findings)

\section{Policy Implications}

[Policy implications can either be: a list of options weighing up different strategies to resolve an issue, or a list of a few grouped recommendations. Sentence explaining if these are competing or complementary options]:

- [Sentence reminding the reader of a policy issue. A few sentences giving a recommendation from the evidence about how to resolve this (What is the recommendation? When does this need to be done? What is the first step?

What would the recommendation achieve? What are the advantages/disadvantages of this option?]

- [As above.]

- [As above.]

(Aim for no more than 3 recommendations)

\section{Key References}

[ List of no more than five relevant publicly accessible articles - note, these do not have to be limited to academic papers.]

\section{Contact Details}

Contact: [Your name] ([Your position] at [Your department], [Your university])

Email: [Your email address]

[Your name] researches [summary of your research area in no more than thirty words]

[Detail of your funders if applicable]

The views expressed in this policy briefing are those of the author and not necessarily those of [your institution] or [your funders]. 


\section{Appendix 2 - Example indicators}

Table 5: (Indicative) Process Indicators to track research policy impact: Assess progress against specific operational activities (adapted from the UCL Policy Impact Unit)

\begin{tabular}{|c|c|c|}
\hline \multirow[b]{2}{*}{ Activity } & \multicolumn{2}{|c|}{ Indicators (italics = taken from REF list) } \\
\hline & Quantitative & Qualitative \\
\hline $\begin{array}{l}\text { Write and } \\
\text { disseminate a } \\
\text { policy brief }\end{array}$ & $\begin{array}{l}\text { Number of people the brief was sent to } \\
\text { Number of views/downloads of the brief } \\
\text { for further information / requests for } \\
\text { meetings }\end{array}$ & $\begin{array}{l}\text { Who the brief was sent to (i.e. their } \\
\text { position, sphere of influence, etc.) } \\
\text { interest in topic } \\
\text { Examples of interactions that demonstrate } \\
\text { (e.g. requests for meetings or further } \\
\text { information) }\end{array}$ \\
\hline $\begin{array}{l}\text { Workshop / } \\
\text { seminar / event } \\
\text { / webinar }\end{array}$ & $\begin{array}{l}\text { Total number of participants } \\
\text { Proportion of participants providing } \\
\text { positive feedback }\end{array}$ & $\begin{array}{l}\text { Feedback comments demonstrating use or } \\
\text { value of workshop } \\
\text { Qualitative feedback from participants or } \\
\text { attendees at research events; did attendees } \\
\text { mention how they used/will use the brief } \\
\text { in their roles? Integrating action (e.g. What } \\
\text { actions will you /did you do as a result of } \\
\text { the event?) } \\
\text { Scheduled follow-ups }\end{array}$ \\
\hline $\begin{array}{l}\text { One-to-one } \\
\text { meeting }\end{array}$ & $\begin{array}{l}\text { Number of meetings held (e.g. following } \\
\text { dissemination of a policy briefing) }\end{array}$ & $\begin{array}{l}\text { Any actions from the meeting(s) e.g. } \\
\text { further opportunities to collaborate } \\
\text { or 'snowball' effect with further new } \\
\text { connections made }\end{array}$ \\
\hline Press release & $\begin{array}{l}\text { Number of stories in media, e.g. TV, } \\
\text { newspapers }\end{array}$ & Quality of representation in the media \\
\hline Social media & $\begin{array}{l}\text { Number of engagements } \\
\text { (e.g. Twitter, Linkedln, Facebook etc.) } \\
\text { Number of shares/retweets } \\
\text { Number of views } \\
\text { Number of blogs }\end{array}$ & \\
\hline Other & $\begin{array}{l}\text { Data to show close working relationships } \\
\text { with members of staff. For example, the } \\
\text { number of meetings held, minutes from these } \\
\text { meetings, membership of working groups, } \\
\text { co-authoring of publications. }\end{array}$ & $\begin{array}{l}\text { Qualitative data such as Reports and } \\
\text { memberships e.g. SAGE or lobbying } \\
\text { groups. }\end{array}$ \\
\hline
\end{tabular}


Table 6: (Indicative) Outcome Indicators to track research policy impact: Assess impact against type of impact sought (adapted from the UCL Policy Impact Unit)

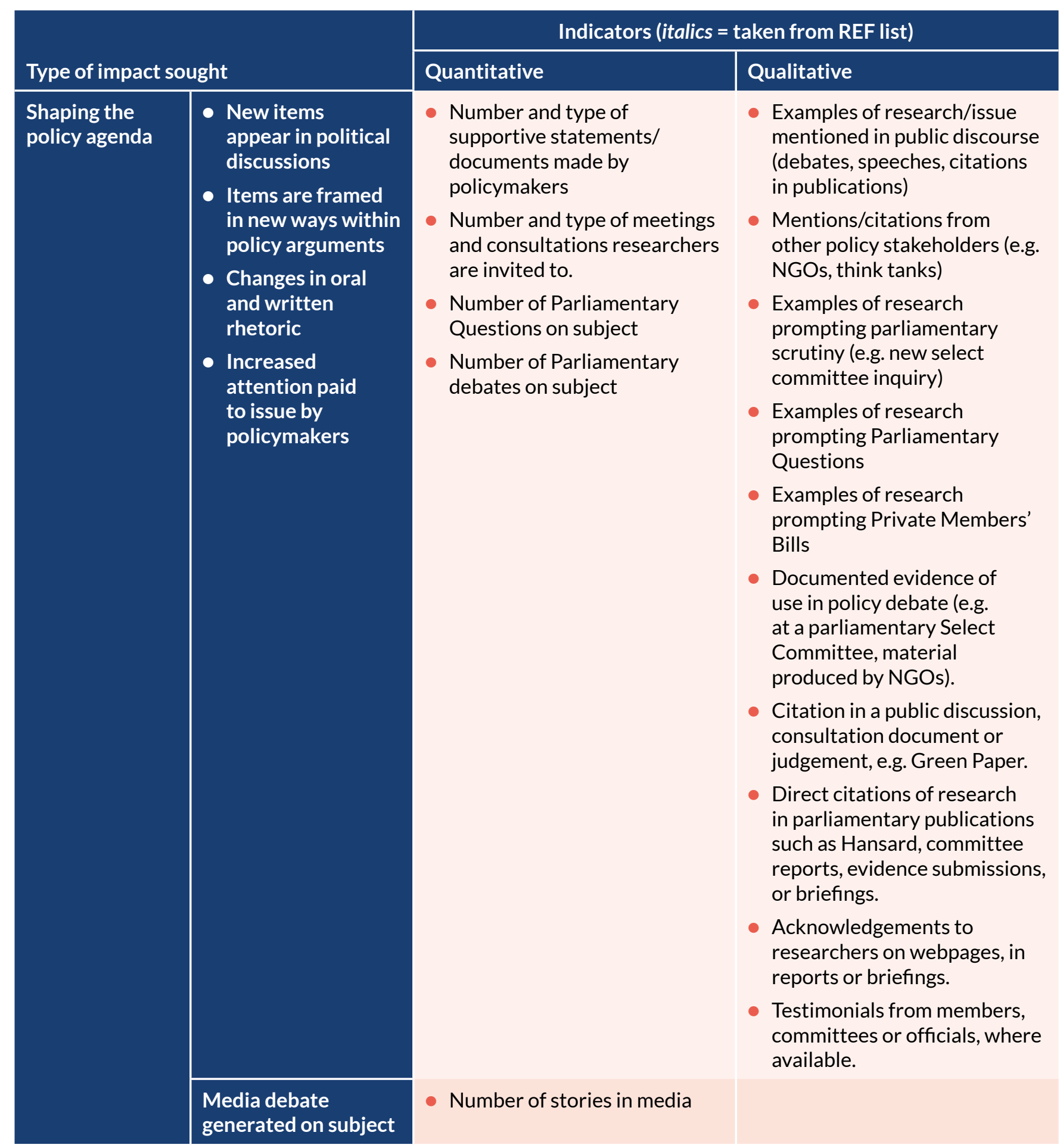


Table 6: (continued)

\begin{tabular}{|c|c|c|c|}
\hline \multirow{2}{*}{\multicolumn{2}{|c|}{ Type of impact sought }} & \multicolumn{2}{|c|}{ Indicators (italics = taken from REF list) } \\
\hline & & \multirow[b]{2}{*}{$\begin{array}{l}\text { Quantitative } \\
\text { Number and type of } \\
\text { supportive communications } \\
\text { and statements made by } \\
\text { policymakers } \\
\text { Number of decision makers } \\
\text { expressing commitment / } \\
\text { willingness to act on issue in } \\
\text { public or private }\end{array}$} & \multirow{2}{*}{$\begin{array}{l}\text { Qualitative } \\
\text { Examples of research/issue } \\
\text { mentioned in public discourse } \\
\text { (debates, speeches, citations } \\
\text { in publications) }\end{array}$} \\
\hline $\begin{array}{l}\text { Influencing } \\
\text { (individual) } \\
\text { policymaker } \\
\text { attitudes and } \\
\text { behaviours }\end{array}$ & $\begin{array}{l}\text { Key decision makers } \\
\text { change rhetoric in } \\
\text { public and private }\end{array}$ & & \\
\hline \multirow[t]{3}{*}{$\begin{array}{l}\text { Contributing } \\
\text { to the } \\
\text { development of } \\
\text { policy }\end{array}$} & $\begin{array}{l}\text { Research evidence } \\
\text { is used to better } \\
\text { understand the } \\
\text { nature of a policy } \\
\text { problem (e.g. causes, } \\
\text { effects and scale) }\end{array}$ & \multirow[t]{3}{*}{$\begin{array}{l}\text { How many times it was } \\
\text { mentioned? } \\
\text { E.g. this was mentioned in } 5 \\
\text { parliamentary reports... }\end{array}$} & \multirow{2}{*}{$\begin{array}{l}\text { Direct citations of research } \\
\text { in parliamentary publications } \\
\text { such as Hansard, committee } \\
\text { reports, evidence submissions, } \\
\text { or briefings. } \\
\text { Acknowledgements to } \\
\text { researchers on webpages, in } \\
\text { reports or briefings. }\end{array}$} \\
\hline & $\begin{array}{l}\text { Research evidence } \\
\text { is used to develop } \\
\text { effective policy } \\
\text { solutions (e.g. } \\
\text { understanding } \\
\text { what has worked } \\
\text { elsewhere or in } \\
\text { the past, costs and } \\
\text { benefits, modelling of } \\
\text { outcomes) }\end{array}$ & & \\
\hline & $\begin{array}{l}\text { Capacity building } \\
\text { (Policy makers } \\
\text { (and wider policy } \\
\text { community) develop } \\
\text { and strengthen } \\
\text { skills, instincts, } \\
\text { abilities, processes or } \\
\text { resources) }\end{array}$ & & $\begin{array}{l}\text { Evidence of use of process/ } \\
\text { technology } \\
\text { Training and career } \\
\text { development of policy } \\
\text { makers? Offer seminars } \\
\text { and consultation to policy } \\
\text { stakeholders or staff (e.g. } \\
\text { AskPRU clinics) }\end{array}$ \\
\hline \multirow[t]{2}{*}{ Change in policy } & $\begin{array}{l}\text { Change in policy } \\
\text { direction }\end{array}$ & & $\begin{array}{l}\text { Documented evidence of } \\
\text { influence on guidelines, } \\
\text { legislation, regulation, policy } \\
\text { or standards. } \\
\text { Documented evidence of } \\
\text { changes to international } \\
\text { development policies. }\end{array}$ \\
\hline & Withdrawal of policy & & $\begin{array}{l}\text { Documented evidence of } \\
\text { impact of lobbying leading to } \\
\text { withdrawal of emerging or } \\
\text { existing policy? }\end{array}$ \\
\hline
\end{tabular}


Table 6: (continued)

\begin{tabular}{|c|c|c|c|}
\hline & & \multicolumn{2}{|c|}{ Indicators (italics = taken from REF list) } \\
\hline \multicolumn{2}{|c|}{ Type of impact sought } & Quantitative & Qualitative \\
\hline \multirow[t]{3}{*}{$\begin{array}{l}\text { Decision making } \\
\text { (legislation) }\end{array}$} & $\begin{array}{l}\text { Introduction of } \\
\text { legislation }\end{array}$ & & \multirow{3}{*}{$\begin{array}{l}\text { Analysis by third- } \\
\text { party organisations of } \\
\text { parliamentary proceedings or } \\
\text { processes, for example studies } \\
\text { of the passage of particular } \\
\text { pieces of legislation. } \\
\text { Set-up of national centres, } \\
\text { infrastructures and } \\
\text { secondment posts e.g. } \\
\text { National Innovation Centres } \\
\text { (“What Works" centres), large } \\
\text { infrastructure announcements } \\
\text { following identification of } \\
\text { need }\end{array}$} \\
\hline & Change of legislation & & \\
\hline & $\begin{array}{l}\text { Budgetary } \\
\text { commitments }\end{array}$ & & \\
\hline \multirow[t]{4}{*}{$\begin{array}{l}\text { Implementation } \\
\text { of commitments }\end{array}$} & $\begin{array}{l}\text { In delivering a } \\
\text { public service, a } \\
\text { new technology or } \\
\text { process has been } \\
\text { adopted or an } \\
\text { existing technology } \\
\text { or process improved }\end{array}$ & \multirow{3}{*}{$\begin{array}{l}\text { Measures of improved public } \\
\text { services, including, where } \\
\text { appropriate, quantitative } \\
\text { information; such information } \\
\text { may relate, for example, to } \\
\text { the quality, accessibility or } \\
\text { cost-effectiveness of public } \\
\text { services. } \\
\text { Satisfaction measures (e.g. } \\
\text { with services). }\end{array}$} & \\
\hline & $\begin{array}{l}\text { The quality } \\
\text { accessibility, } \\
\text { acceptability or } \\
\text { cost-effectiveness of } \\
\text { a public service has } \\
\text { been improved }\end{array}$ & & \\
\hline & $\begin{array}{l}\text { Research is used } \\
\text { to change current } \\
\text { processes or } \\
\text { services or identify } \\
\text { new services to be } \\
\text { provided }\end{array}$ & & \\
\hline & $\begin{array}{l}\text { Building networks } \\
\text { and coalitions }\end{array}$ & $\begin{array}{l}\text { Number of policy makers } \\
\text { approaching researchers for } \\
\text { information unprompted } \\
\text { following interaction }\end{array}$ & \\
\hline
\end{tabular}




\section{References}

1. Cairney P, Kwiatkowski R. How to communicate effectively with policymakers: combine insights from psychology and policy studies. Palgrave Communications 2017;3(1) doi: 10.1057/s41599-017-0046-8

2. Oliver K, Cairney P. The dos and don'ts of influencing policy: a systematic review of advice to academics. Palgrave Communications 2019;5(1) doi: 10.1057/ s41599-019-0232-y

3. Ffrench-Constant L. How to Plan, Write and Communicate an Effective Policy Brief: Three Steps to Success. https://www.researchtoaction.org/2014/10/ plan-write-communicate-effective-policy-brief-threesteps-success/, 2014.

4. Jones $\mathrm{N} \&$ Walsh C. Policy Briefs as a communication tool for development research. http://www.odi.org.uk/ sites/odi.org.uk/files/odi-assets/ publications-opinionfiles/594.pdf, 2008.5. Wolfe, R. (2013). <POLICY BRIEFS. A guide to writing policy briefs for research uptake. LSHTMblogs.pdf>.

5. Young, E. \& Quinn, L. (2012) Making Research Evidence Matter: A Guide to Policy Advocacy in Transition Countries. [Online Publication - International Centre for Policy Advocacy]. Available from: http://advocacyguide. icpolicyadvocacy.org

6. Greer, S. L., Vasev, N., Jarman, H., Wismar, M., \& Figueras, J. (2019). It's the governance, stupid!: TAPIC: a governance framework to strengthen decision making and implementation. European Observatory on Health Systems and Policies.

7. Whitty CJ. What makes an academic paper useful for health policy? BMC Med 2015;13:301. doi: 10.1186/ s12916-015-0544-8 [published Online First: 2015/12/18]

8. Young E, \& Quinn, L. . An Essential Guide to writing Policy Briefs.pdf. https://www.icpolicyadvocacy.org/sites/icpa/ files/downloads/icpa_policy_briefs_essential_guide.pdf, 2017

9. Stewart R, Langer L, Erasmus Y. An integrated model for increasing the use of evidence by decision-makers for improved development. Development Southern Africa 2018;36(5):616-31.doi: 10.1080/0376835x.2018.1543579
10. Petkovic J, Welch, V., Jacob, M.H., Yoganathan, M., Ayala, A.P., Cunningham, H., Tugwell,P. . Do evidence summaries increase health-policy makers' use of evidence from systematic reviews? A systematic review. Campbell Systematic Reviews 2018;2018:8 doi: DOI: https://doi.org/10.4073/csr.2018.8

11. Langer L, Tripney J, Gough DA. The science of using science: Researching the use of research evidence in decision-making: UCL Institute of Education, EPPICentre 2016.

12. Wong SL, Green LA, Bazemore AW, et al. How to write a health policy brief. Fam Syst Health 2017;35(1):2124. doi: 10.1037/fsh0000238 [published Online First: 2016/12/10]

13. Eisele, $F$ (n.d.). Preparing a Policy Brief Issue [PDF Document]. Available at: https://www.courses.psu.edu/ hpa/hpa301_fre1/IBInstructions_fa02.PDF

14. Weyrauch, V., and D'Agostino, J. (2012). How to communicate research for policy influence. Toolkit No.2: Policy briefs. Buenos Aires. CIPPEC. < Guia-02-serie-3ingles.pdf>.

15. Crow D, Jones M. Narratives as tools for influencing policy change. Policy \& Politics 2018;46(2):217-34. doi: 10 .1332/030557318×15230061022899

16. Mayne R, Green D, Guijt I, et al. Using evidence to influence policy: Oxfam's experience. Palgrave Communications 2018;4(1) doi: 10.1057/s41599-018-0176-7

17. Kerr EA, Riba M, Udow-Phillips M. Helping health service researchers and policy makers speak the same language. Health Serv Res 2015;50(1):1-11. doi: 10.1111/14756773.12198 [published Online First: 2014/07/22]

18. Bednarek AT, Shouse B, Hudson CG, et al. Science-policy intermediaries from a practitioner's perspective: The Lenfest Ocean Program experience. Science and Public Policy 2016;43(2):291-300. doi: 10.1093/scipol/scv008

19. Alla K, Hall WD, Whiteford HA, et al. How do we define the policy impact of public health research? A systematic review. Health Research Policy and Systems 2017;15(1):84. doi: 10.1186/s12961-017-0247-z

20. Masset E, Gaarder M, Beynon P, et al. What is the impact of a policy brief? Results of an experiment in research dissemination. Journal of Development Effectiveness 2013;5(1):50-63. doi: 10.1080/19439342.2012.759257 
21. Kuruvilla S, Mays N, Walt G. Describing the impact of health services and policy research. Journal of Health Services Research \& Policy 2007;12(1_suppl):23-31. doi: 10.1258/135581907780318374

22. Mazzucato M, Kattel, R., Albala, S., Dibb, G., McPherson, M. Voldsgaard, A. Alternative policy evaluation frameworks and tools, BEIS Research Paper Number 2020/04: UCL Institutue for Innovation and Public Purpose (IIPP), https://medium.com/policypostings/dissemination-is-dead-so-do-this-insteade836ced8c5c, October 2020.

23. Yusof MM, Papazafeiropoulou A, Paul RJ, et al. Investigating evaluation frameworks for health information systems. Int J Med Inform 2008;77(6):37785. doi: 10.1016/j.ijmedinf.2007.08.004 [published Online First: 2007/10/02]

24. West R, Michie S., Atkins, L. Chadwick, P. \& Lorencatto, F. (2019). Achieving behaviour change: A guide for local government and partners. Available at: https:// assets.publishing.service.gov.uk/government/uploads/ system/uploads/attachment_data/file/875385/PHEBI_ Achieving_Behaviour_Change_Local_Government.pdf: Public Health England, 2019.

25. University of Sussex. Guidelines on how to write a research or policy briefing. Available at: https://blogs. sussex.ac.uk/policy-engagement/resources-forresearchers/guidelines-on-how-to-write-a-research -or-policy-briefing/.

26. Ozburn L. Debunking Policy Briefs and Beyond: A BestPractices Guide for Graduate Students EUC Paper Series, Maeus Talk MS Library \& Information Science European Union Center, iSchool, University of Illinois at UrbanaChampaign.

27. Staley K. There is no paradox with PPI in research. J Med Ethics. 2013;39(3):186-7.

28. Evidence Search, Process Guide, National Institute of Health and Care Excellence. Available at: https://www. nice.org.uk/about/what-we-do/evidence-services/ evidence-search/evidence-search-content

29. Sculpher, M., Palmer, S. After 20 Years of Using Economic Evaluation, Should NICE be Considered a Methods Innovator?. PharmacoEconomics 38, 247-257 (2020). https://doi.org/10.1007/s40273-019-00882-6
30. Presseau, J., McCleary, N., Lorencatto, F. et al. Action, actor, context, target, time (AACTT): a framework for specifying behaviour. Implementation Sci 14, 102 (2019). https://doi.org/10.1186/s13012-019-0951-x

31. Kicinski M.How does under-reporting of negative and inconclusive results affect the false-positive rate in metaanalysis? A simulation studyBMJ Open 2014;4:e004831. doi: 10.1136/bmjopen-2014-004831

32. UCL Public Policy Unit. Informing Public Policy: A guide for UCL Researchers \& Staff. January 2021. https://www.ucl.ac.uk/public-policy

33. UK Parliament. Research Impact on Policy. Available at: https://www.parliament.uk/globalassets/assets/ teams/post/research_impact_on_policy_briefing_ document_june21.pdf?utm_source=KMroundup\&utm_ medium=email\&utm_campaign=riop

34. Carrie L. Conaway, 2013. "The Problem with Briefs, in Brief," Education Finance and Policy, MIT Press, vol. 8(3), pages 287-299, July.

35. The Women's and Children's Health Policy Center, "Writing Policy Briefs: A Guide to Translating Science and Engaging Stakeholders".

36. Parliamentary Office for Science and Technology (POST). How to Write a Policy Briefing. Available at: https://post. parliament.uk/how-to-write-a-policy-briefing/ 


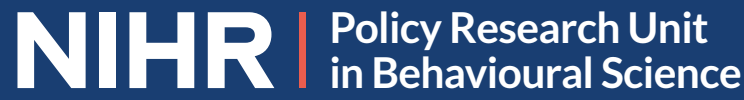
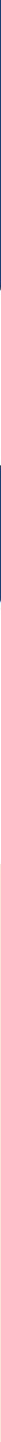